\title{
EFEK STRATEGI KOMUNIKASI PEMASARAN PADA LOYALITAS PELANGGAN APOTEK K-24 MULYOSARI
}

\section{MARKETING COMMUNICATION STRATEGY EFFECTS ON CUSTOMERS LOYALTY OF K-24 PHARMACY MULYOSARI}

\author{
Dedy Ayub Wicaksono \\ Fotografer dan Penulis PT. PP Properti (TBK) \\ Email : dedyayub@gmail.com
}

\begin{abstract}
Marketing communication strategy is one of the first in order to introduce products and services to consumers, and will be very important because it will be related to the benefits obtained from the company. Mulyosari K-24 Pharmacy applies a marketing communication strategy by providing convenience in every service. One of them is by providing several service features via the internet. This marketing strategy by providing convenience will affect customers and potential customers in terms of changing attitudes. Customers who are satisfied with the quality of services and products sold will influence the good image and produce loyal customers. Customers who are loyal will continue to use the brand, even though they are faced with many alternative brands of their competitors. This study was conducted to examine the effect of marketing communication strategies on customer loyalty of Mulyosari K-24 Pharmacy. The researcher used marketing communication theory and attitude change theory which later will produce Brand Loyalty, the method used in this study is: descriptive quantitative method with the process of collecting data using a survey method in the form of a questionnaire. Based on the results of hypothesis testing, the researcher obtained the results that Ha was accepted which meant that the marketing communication strategy had a significant effect on customer loyalty at Pharmacy K24 Mulyosari, then from data analysis using simple linear regression, the researcher obtained results that the marketing communication strategy affected $51 \%$ of customer loyalty Mulyosari K-24 Pharmacy has a correlation value (R) of 0.714 which shows a strong category, because Apotek K-24 customers are very responsive with the ease of services provided by the Pharmacy company K24 Mulyosari.
\end{abstract}

Keywords: Marketing Communication Strategy, Customer Loyalty, Pharmacy K-24, Potential Customers

\footnotetext{
ABSTRAK

Strategi komunikasi pemasaran merupakan salah satu awal dalam rangka mengenalkan produk dan jasa kepada konsumen, dan akan menjadi sangat penting karena akan berkaitan dengan keuntungan yang didapat dari perusahaan. Apotek K24 Mulyosari menerapkan strategi komunikasi pemasaran dengan memberikan kemudahan disetiap pelayanannya. Salah satunya dengan memberikan beberapa fitur layanan via internet. Strategi pemasaran dengan memberikan kemudahan ini akan mempengaruhi pelanggan maupun calon pelanggan dalam hal perubahan

ISSN 2338 - 0861 (cetak); e-ISSN 2621 - 8712 (online)

website : http://spektrum.stikosa-aws.ac.id
} 
sikap. Pelanggan yang puas akan kualitas layanan dan produk yang dijual akan berpengaruh pada citra baik dan menghasilkan pelanggan yang loyal. Pelanggan yang setia akan melanjutkan penggunaan merek tersebut, walaupun dihadapkan dengan banyak alternative merek produk pesaingnya. Penelitian ini dilakukan untuk menguji pengaruh strategi komunikasi pemasaran terhadap loyalitas pelanggan Apotek K-24 Mulyosari. Peneliti menggunakan teori komunikasi pemasaran dan teori perubahan sikap yang nantinya akan menghasilkan Brand Loyality (loyalitas pelanggan), metode yang digunakan dalam penelitian ini yaitu : metode kuantitatif deskriptif dengan proses pengumpulan data menggunakan metode survei berupa kuesioner. Berdasarkan hasil dari pengujian hipotesis, maka penelti memperoleh hasil bahwa Ha diterima yang berarti strategi komunikasi pemasaran berpengaruh signifikan terhadap loyalitas pelanggan Apotek K24 Mulyosari, kemudian dari analisa data menggunakan regresi linier sederhana, peneliti memperoleh hasil bahwa strategi komunikasi pemasaran memberikan pengaruh 51\% terhadap loyalitas pelanggan Apotek K-24 Mulyosari dengan memiliki nilai korelasi (R) sebesar 0,714 yang menunjukkan kategori kuat, sebab pelanggan Apotek K-24 sangat responsif dengan kemudahan layanan yang diberikan oleh perusahaan Apotek K24 Mulyosari.

Kata-kata Kunci: Strategi Komunikasi Pemasaran, Loyalitas Pelanggan, Apotik K24, Pelanggan Potensial

\section{PENDAHULUAN}

Komunikasi pemasaran dilakukan oleh berbagai perusahaan, termasuk didalamnya pada industri farmasi. Di era digital saat ini, persaingan bisnis di bidang farmasi semakin ketat, sedangkan perusahaan dituntut agar dapat mempertahankan serta membangun loyalitas pelanggan dengan meningkatkan kualitas pelayanannya, serta menerapkan strategi yang tepat dalam hal menghadapi komplain dari pelanggan. Strategi komunikasi pemasaran sendirir merupakan salah satu awal dalam rangka mengenalkan produk pada konsumen dan ini akan menjadi sangat penting karena akan berkaitan dengan keuntungan yang akan diperoleh oleh perusahaan. Menurut Tjiptono (2008 : 219) komunikasi pemasaran adalah aktivitas yang berusaha menyebarkan informasi, mempengaruhi/membujuk dan atau mengingatkan pasar sasaran atas perusahaan dan produknya agar bersedia menerima, membeli dan loyal pada produk yang ditawarkan perusahaan yang bersangkutan. Dalam hal ini komunikasi pemasaran juga dapat dinyatakan sebagai kegiatan komunikasi yang ditujukan untuk menyampaikan pesan kepada konsumen dan pelanggan dengan menggunakan sejumlah media dan berbagai saluran yang dapat dipergunakan dengan harapan terjadinya tahap perubahan, yaitu perubahan pengetahuan, perubahan sikap, dan perubahan tindakan.

Apotek K24 selaku pelaku bisnis dibidang farmasi ini menerapkan strategi komunikasi pemasarannya dengan meningkatkan pelayanannya menggunakan Integrated Marketing Communication (komunikasi pemasaran terpadu), lewat websitenya yang bernama www.apotek-k24.com. Perusahaan ini memberikan beberapa layanan dan promosi lewat websitenya yang terintegrasi dan memudahkan

ISSN 2338 - 0861 (cetak); e-ISSN 2621 - 8712 (online)

website : http://spektrum.stikosa-aws.ac.id 


\begin{abstract}
pelanggannya untuk mencari informasi seputar kesehatan. Berdasarkan konsep Integrated Marketing Communication, perusahaan secara saksama memadukan dan mengkoordinasikan semua bauran pemasaran (alat promosi) untuk menyampaikan pesan yang jelas, konsisten, dan memiliki pengaruh kuat. Selain itu Integrated Marketing Communication juga dapat membentuk identitas merek yang kuat dengan mengikat bersama serta memperkuat citra dan pesan yang ingin disampaikan oleh perusahaan.

Dalam hal ini peneliti tertarik untuk meneliti "Pengaruh Strategi Komunikasi Pemasaran terhadap Loyalitas Pelanggan Apotek K-24 Mulyosari" Dari uraian latar belakang masalah diatas, maka peneliti merumuskan masalah sebagai "Bagaimana pengaruh strategi komunikasi pemasaran Apotek K24 terhadap loyalitas pelanggannya?"
\end{abstract}

\section{METODOLOGI}

Peneliti menggunakan metode survey dimana nantinya peneliti akan melakukan survey dengan mengumpulkan data yang sifatnya sangat terstruktur dan mendetail melalui kuesioner sebagai instrument utama untuk mendapatkan informasi dari sejumlah responden yang diasumsikan mewakili populasi secara spesifik. (Kriyanto 2012:59).

Peneliti menggunakan teori komunikasi pemasaran dan teori perubahan sikap yang nantinya akan menghasilkan Brand Loyality (loyalitas pelanggan).Jenis penelitian yang digunakan adalah kuantitatif deskriptif, yang dimana nantinya peneliti akan melakukan riset dengan cara pengumpulan data dari kuesioner. Data yang dihasilkan dari kuesioner berupa angka, dan nantinya data tersebut berupa tabel, lalu peneliti akan mengolah kemudian menganalisa data tersebut. Sugiyono (2013) dalam bukunya menjelaskan metode ini nantinya digunakan oleh peneliti untuk meneliti pada populasi atau sampel tertentu dengan menggunakan teknik pengambilan sampel pada umumnya, yatu dilakukan secara random atau acak, pengumpulan data menggunakan instrument penelitian, analisis data bersifat kuantitatif/statistic dengan tujuan untuk menguji hipotesis yang telah ditetapkan. Populasi dari penelitian ini adalah pelanggan Apotek K-24 di Mulyosari Surabaya. Peneliti mengambil populasi pelanggan Apotek K-24 di wilayah Mulyosari, karena Apotek K-24 Mulyosari adalah Apotek Acuan atau Apotek pelopor untuk APotek-Apotek lain yang ada di Surabaya, sebab pelanggan yang ada di Mulyosari lebih banyak, dari data member yang didapat sebanyak 2.360 pelanggan member aktif per Februari.

\section{HASIL DAN PEMBAHASAN}

Dalam penelitian ini peneliti menggunakan teknik sampling Probability Sampling yaitu simple random sampling, pengambilan sampel anggota populasi yang dilakukan secara acak tanpa memperhatikan strata yang ada didalam populasi terebut. Penelitian ini bertujuan untuk mengetahui strategi komunikasi pemasaran terhadap pengaruh brand loyalty (loyalitas pelanggan) Apotek K24 Mulyosari Surabaya, maka peneliti akan menyebarkan kuesioner secara acak kepada pelanggan Apotek K24 Mulyosari yang sedang berbelanja, akan tetapi peneliti juga menentukan beberapa kriteria agar data yang diterima valid, kriteria yang telah 
ditetapkan oleh peneliti adalah masyarakat yang sedang berbelanja di apotek K24 Mulyosari Surabaya, dengan catatan bahwa setiap pembeli yang sedang berbelanja di Apotek K24 tergolong dewasa atau pembeli langsung, dan memang ingin berbelanja obat di tempat tersebut tanpa menyuruh pihak kedua atau perantara.

Berdasarkan dari hasil perhitungan pengolahan dengan menggunakan program SPSS for Windows Version 16.0 maka diperoleh persamaan regresi linier sederhana pada tabel berikut ini :

Tabel 1. Tabel hasil pengolahan data persaman regresi (SPPS)

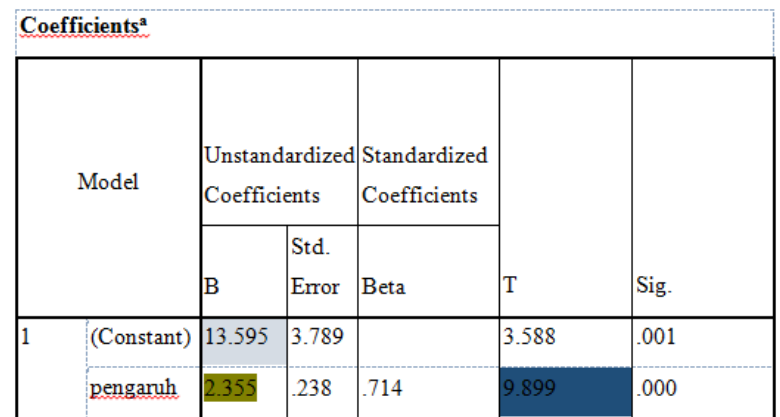

Berdasarkan

hasil perhitungan diatas, diperoleh persamaan regresi linier sederhana sebagai berikut:

$\mathrm{Y}=13.595+2.355 \mathrm{X}$

$\mathrm{Y}=$ Loyalitas pelanggan Apotek K24 Mulyosari

$\mathrm{X}=$ Pengaruh strategi komunikasi pemasaran

Adapun intrepretasi dari model regresi linier sederhana di atas adalah sebagai berikut:

- Konstan (a) yang dihasilkan sebesar 13.595 menunjukkan bahwa loyalitas pelanggan Apotek K24 Mulyosari (Y) sebesar 13.595 satu-satuan jika variabel pengaruh strategi komunikasi pemasaran (X), bernilai konstan.

- Nilai koefisien pengaruh strategi komunikasi pemasaran sebesar 2.355 menunjukkan bahwa variabel pengaruh strategi komunikasi pemasaran (X) ditingkatkan satu-satuan maka akan mengakibatkan loyalitas pelanggan sebesar $(\mathrm{Y})$ sebesar 2.355 dengan asumsi variabel lain konstan.

\section{Tabel 2. Tabel hasil analisa regresi}

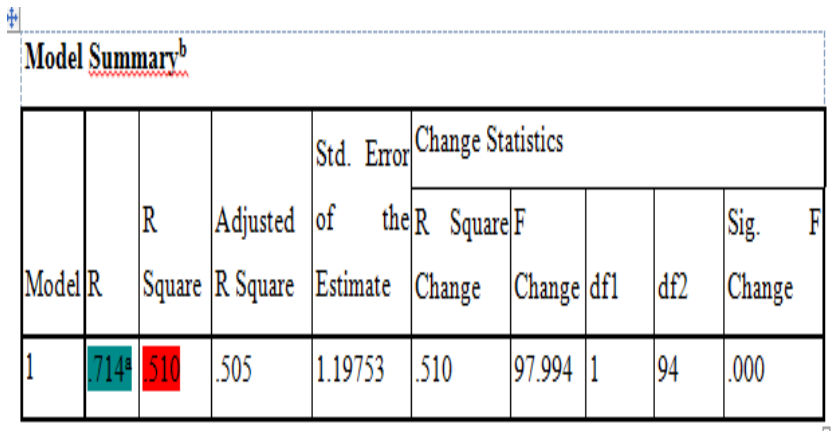

$\mathrm{a}=$ Predictors: (Constant), pengaruh $\mathrm{b}=$ Dependent Variable: Loyalitas

Nilai koefisien korelasi (R) menunjukkan seberapa hubungan erat antara variabel pengaruh strategi komunikasi pemasaran (X) dengan variabel Loyalitas pelanggan Apotek K24 Mulyosari (Y).

Besarnya nilai koefisien korelasi adalah sebesar 0.714. nilai tersebut menunjukkan hubungan variabel pengaruh strategi komunikasi pemasaran (X) dengan variabel Loyalitas pelanggan Apotek K24 Mulyosari (Y) bernilai kuat karena nilai korelasi tersebut berada pada 0.600-0.799.

Dari hasil analisis regresi linear sederhana diperoleh nilai koefisien sebesar 0.510 yang menunjukkan bahwa kontribusi pengaruh variabel pengaruh strategi

ISSN 2338 - 0861 (cetak); e-ISSN 2621 - 8712 (online) website : http://spektrum.stikosa-aws.ac.id 
komunikasi pemasaran terhadap loyalitas pelanggan Apotek K24 Mulyosari sebesar 51\%, sedangkan sisanya dipengaruhi oleh variabel lain diluar model yang diteliti.

Hipotesis :

- Ha: $\beta 1 \neq 0$ ( artinya, variabel Strategi komunikasi pemasaran (X) mempunyai pengaruh yang signifikan terhadap variabel Loyalitas pelanggan Apotek K24 Mulyosari.

- Ho: $\beta 1=0$ (artinya variabel pengaruh strategi komunikasi pemasaran $(\mathrm{X})$ tidak mempunyai pengaruh yang signifikan terhadap loyalitas pelanggan Apotek K24 Mulyosari.

Kaidah keputusan:

1. Jika nilai thitung $\leq$ ttabel, maka Ho diterima dan Ha ditolak, artinya tidak signifikan.

2. Jika nilai thitung $\geq$ ttabel, maka Ho ditolak dan Ha diterima, artinya signifikan.

Tabel Coefficients diperoleh $\mathrm{t}$ hitung $=$ 9.899 prosedur mencari straistik tabel dengan kriteria :

- Tingkat signifikan (Tingkat signifikan $(\alpha=0,05)$ untuk uji dua pihak

- df atau dk (derajat kebebasan) $=$ jumlah data $-2=96-2=94$

- $\quad$ sehingga didapat $t_{\text {tabel }}=1.665$

Berdasarkan output SPSS versi 16.0 di peroleh $t$ hitung sebesar 9.899 lebih besar dari tabel 1.665 maka Ha diterima dan Ho ditolak. Sehingga kesimpulannya ada pengaruh strategi komunikasi pemasaran $(X)$ terhadap loyalitas pelanggan Apotek K24 Mulyosari (Y).
Berdasarkan hasil survey dan penyebaran kuesioner yang telah dilakukan, maka hasil yang didapat dari penelitian ini, Strategi komunikasi pemasaran Apotek K24 berpengaruh signifikan terhadap loyalitas pelanggan Apotek K24 Mulyosari. hal ini diketahui dari perhitungan uji statistik. Berdasarkan hasil dari analisis regresi linier sederhana diketahui bahwa variabel pengaruh strategi komunikasi pemasaran (X) terhadap loyalitas pelanggan Apotek K24 Mulyosari memperoleh hasil persamaan regresi :

$$
Y=13.595+2.355 X \text {. }
$$

Pada persamaan nilai diatas nilai konstan (a) yang dihasilkan sebesar 13.595 yang berarti bahwa skor pada variabel pengaruh strategi komunikasi pemasaran terhadap loyalitas pelanggan Apotek K24 Mulyosari sebesar 2.355. Sedangkan nilai korelasi (R) sebesar 0.714 , hal ini menunjukkan bahwa variabel bebas pengaruh strategi komunikasi pemasaran $(\mathrm{X})$ dan variabel loyalitas pelanggan Apotek K24 Mulyosari mempunyai nilai kuat.

Sedangkan dari perhitungan nilai koefisien determinasi yang didapat sebesar 0.510. Artinya bahwa variabel bebeas (independent) pengaruh strategi komunikasi pemasaran (X) terhadap loyalitas pelanggan Apotek K24 Mulyosari (Y) sebesar (51\%) sedangkan sisanya dipengaruhi oleh faktor lain diluar penelitian. Hal ini juga diperkuat dari pernyataan responden yang menyatakan, sebagian besar responden pernah berbelanja di Apotek K24 Mulyosari lebih dari 3 kali sebanyak 71.9\%. kemudian sebanyak $60.4 \%$ responden menjadi pelanggan tetap di Apotek K24 Mulyosari. 


\section{KESIMPULAN}

Hasil dari uji analisis data yang menunjukkan bahwa strategi komunikasi pemasaran berpengaruh terhadap loyalitas pelanggan Apotek K24 Mulyosari Surabaya. Hal ini dibuktikan pada tabel 1.29 dengan $\mathrm{t}$ hitung sebesar 9.899 yang lebih besar dari $t$ tabel 1665 sehingga hipotesis diterima yang berarti strategi komunikasi pemasaran berpengaruh signifikan terhadap loyalitas pelanggan Apotek K24 Mulyosari Surabaya.

Strategi komunikasi pemasaran memberikan pengaruh terhadap loyalitas pelanggan Apotek K24 Mulyosari. Hal ini ditunjukkan pada tabel 1.30 dari uji regresi linier sederhana menghasilkan tingkat pengaruh sebesar 51\%, sedangkan untuk nilai koefisien dalam regresi linier sederhana sebesar 0,714 yang termasuk katergori kuat. Hal ini dikarenakan pelayanan serta kualitas produk yang diberikan perusahaan Apotek K24 Mulyosari dinilai memuaskan pelanggan. Dengan demikian citra dari perusahaan akan menjadi baik, citra perusahaan yang baik nantinya akan menimbulkan loyalitas dari pelanggan..

\section{DAFTAR PUSTAKA}

Durianto, Darmadi, Sugiarto dan Tony Sitinjak. 2004. Strategi Menaklukan Pasar Melalui Riset Ekuitas dan Perilaku Merek. Jakarta : Pt Gramedia Pustaka Utama.

Hurriyati, Ratih. 2005. Bauran Pemasaran dan Loyalitas Konsumen. Alfabet, Bandung.

Kotler, Phillip. 1997. Manajemen Pemasaran: Analisis, Perencanaan, Implementasi dan
Kontrol. Alih Bahasa Hendra Teguh,SE,AK. Jakarta:Airlangga

Kotler,P. (1992). Manajemen Pemasaran. Jakarta: PT. Gelora Aksara Pratama

Kotler,P. \& Armstrong,G. (2008). Prinsip-Prinsip Pemasaran. Jakarta: Erlangga

Kotler,P. \& Keller, K, L. (2009b). Manajemen Pemasaran. Jakarta: Erlangga.

Sutisna. 2002. Perilaku Konsumen dan Komunikasi Pemasaran. Bandung : Penerbit PT. Remaja Rosdakarya Bandung.

Sugiyono. 2013. Metode Penelitian Kuantitatif, Kualitatif, dan R\&D. Bandung : Alfabeta

Tjiptono, Fandy. 2008. Strategi Pemasaran. Edisi 3. Yogyakarta : Andi

Priansa, Donni Juni. 2017. Komunikasi Pemasaran Terpadu Pada Era Media Sosial. CV Pustaka Setia. Bandung.

Non Buku :

Apotek K-24 Indonesia. 2016. [Online] Available att www.apotekk24.com.

Christian A.D Selang. 2013. Pengaruh Bauran Pemasaran Terhadap Loyalitas Konsumen Pada Fresh Mart Bahu Mall Manado. Jurnal Emba. Vol 1 No.3 Juni 2013, Hal 71-80.

Naima Eren Jasmine Nurjanah. 2017. Pengaruh Ekuitas Merek Terhadap Kepuasan dan Loyalitas Konsumen Pada Jenis Merek Susu Cair Dalam Kemasan. Departemen Agribisnis Fakultas Ekonomi dan Manajemen Institut Pertanian Bogor. Skripsi. 